\title{
Application of Earned Value Method in Project Cost Management and Schedule Management
}

\author{
Wenjing $\mathrm{Xu}^{*}$ \\ Xi'an Shiyou University, Xi'an 710065, Shaanxi Province, China \\ *Corresponding author: Wenjing Xu, mma0405@sina.com
}

\begin{abstract}
At present, with the rapid development of China's economy, the development of the construction industry has made a new breakthrough. Project management requires the construction industry to continuously play its role and value in improving the ability of project management. Earned value method, which is an important way in the field of project management, enables whole project management to rise to a new height. The specific principle of earned value method will be elaborated by fully introducing the specific role of earned value method in engineering projects to provide a reference and basis for practitioners to improve their management ability.
\end{abstract}

Keywords: Earned value method; Engineering project; Cost management

Publication date: August 2021; Online publication: August 30, 2021

\section{Introduction}

At present, a large number of modern construction projects are springing up. Construction projects are moving towards a higher and stronger direction where high-rise buildings, super high-rise buildings, and some large construction projects occupy a large proportion ${ }^{[1]}$. At the same time, they also lead to the fierce competition in the construction market in which people are paying much more attention to the meaning of "cost." Everyone has cost in their daily lives. The production and operation of enterprises also include cost. Cost can be large or small, and it is reflected in various ways. Construction project cost is complex and changeable in which it is determined by its own characteristics where a complete construction project from the start of a construction means that it is a multi-component body in the process of construction with personnel, materials, equipment, and other unforeseen factors. From the initial investment decision-making to the final completion and putting it into use, there are many factors that may affect the normal implementation of a project. The construction project cost is generated with the implementation of the project whereby the complexity of a project determines the complexity of the project cost. It is not only affected by a series of interrelated activities within the engineering project, but also by a large number of external unforeseen factors ${ }^{[2,3]}$. If these factors are not identified and analyzed well, it would lead to the failure of cost management, thus affecting the realization of engineering construction goals, leading to serious loss of funds and market competitiveness. Therefore, the cost management of an engineering project is particularly important ${ }^{[4]}$.

In the cost management of engineering projects, there are three important indicators to measure cost management which involve engineering cost, construction period, and engineering quality. Among them, cost management is the key basic work that can directly reflect the profitability of construction enterprises [5]. The significance of cost management is that it has a great influence on the survival and development of construction enterprises in the current market competition environment. The ultimate goal of project cost management is to create value for enterprises ${ }^{[6]}$. Generally, an enterprise will manage the cost by making 
detailed plans, measures and objectives, as well as use various means to achieve the time limit and quality objectives set in the contract. If the manager of a construction enterprise can establish a good project management system in constantly optimizing the cost management to upgrade the project management ability, the cost management can be more reasonable. In a project construction, the cost management should be the top priority of project management ${ }^{[7]}$. Based on the principle of earned value management, this paper explores the specific application of earned value method in project cost management and schedule management, as well as clarifies the important role of earned value method, which does not only ensure the completion of the whole project on schedule but also takes into account the timely adjustment of the project while ensuring certain benefits and effects. At present, due to large and complex personnel involved in construction departments, the earned value method has not been widely used and the related optimization research is still in progress.

\section{Principle of earned value management}

Earned value management is also known as earned value method. Its core purpose is to calculate and compare the difference between the actual cost and the calculated cost in the project to predict and adjust the remaining tasks of the next project in all aspects according to the deviation value of content, time, quality, and cost in combination with the project schedule and its needs. It is a method to control project schedule and cost by calculating cost. The earned value method involves the management methods of project management and other aspects. The concept of earned value method, which appeared since 1990, has been widely used in the world's project management. Through planning and prediction of a project, scientific and reasonable management as well as control measures are implemented for the project where a series of management and prediction methods are carried out. The difference analysis of earned value management does not only include the quality of a specific content, but also the difference of specific construction cost and project schedule. The realization of project cost management needs to be determined by combining with the actual work effect rather than simply comparing the actual value with the planned value, or the progress budget of the project task with the actual project progress. Project management introduced the concept of earned value many years ago, which means that actual work has a multidimensional relationship with its corresponding cost, and it creates a bridge between the plan and the reality.

\subsection{Three basic indicators of earned value management}

Before understanding the application of earned value management, there is a need to be familiar with the meaning of earned value as discussed above. The so-called earned value method is used to analyze the difference between the planned progress and the actual progress of the project through data in order to carry out more beneficial investigation and prediction for the follow-up work. The difference analysis includes construction content, construction quality, construction cost, etc.

In earned value management, three basic indicators should be understood.

(1) Plan value (PV) is the cost of completing a project according to the established plan. It can also be understood as the budgeted cost of work scheduled (BCWS) when the plan is completed. BCWS is directly related to the workload of the project in which it can be expressed as BCWS = planned work $\times$ budget quota. Plan value is defined as the work allocation and approved budget for the progress of planned activities. In statistical theory, this variable can be regarded as "P0" in the compilation of comprehensive index $\times \mathrm{Q} 0$.

(2) Earned value (EV) is the budget cost corresponding to the work has actually been completed, and it can also be understood as the budgeted cost of work performed (BCWP). The completion that is mentioned here includes the quantity of work and the quality requirements. The so-called realized 
value can reflect the progress of the project task and whether it is in accordance with the contract plan. This variable can be regarded as "P0" in the compilation of the comprehensive index $\times \mathrm{Q} 1$.

(3) Actual cost (AC) is the actual cost of work performed (ACWP). This index can reflect the actual expenditure after the completion of the project, and it does not involve the budget cost. Therefore, this variable can be regarded as "P1" in the compilation of the composite index in the principle of statistics $\times$ Q1.

\subsection{Five important management indexes of earned value management}

Based on the above three indicators, another five important management indicators can be obtained through the relationship between different indicators to evaluate the progress of a project.

(1) Cost variance $(\mathrm{CV})$ is the difference between actual cost and earned value. $\mathrm{CV}=\mathrm{EV}-\mathrm{AC}$. CV greater than 0 means saving cost whereas $\mathrm{CV}$ less than 0 means wasting cost.

(2) Schedule variance (SV) is the difference between planned value and earned value. SV $=\mathrm{EV}-\mathrm{PV}$. $\mathrm{SV}$ greater than 0 means progress ahead of schedule whereas SV less than 0 means progress delay.

(3) Cost performance index (CPI) is the ratio of earned value to actual cost. $\mathrm{CPI}=\mathrm{EV} / \mathrm{AC}$ where $\mathrm{CPI}$ greater than 1 indicates that the actual cost of the project is less than the budget.

(4) Schedule performance index (SPI) is the ratio of earned value to planned value. SPI = EV / PV where SPI greater than 1 indicates that the actual progress of the project exceeds the plan.

(5) Estimate at completion (EAC) is the ratio of total budget cost and cost performance index. EAC $=$ BAC / CPI.

\subsection{Advantages and disadvantages of earned value method}

Earned value method combines cost with project schedule as well as quantifies the abstract schedule. It has many advantages. First of all, the earned value method represents the cost, time, and other data as a curve, which is very intuitive. At the same time, it can express some problems and provide reference for the early warning system. Secondly, earned value method is able to predict the possibility of a project delay and cost overrun in addition to provide the possibility of taking corrective measures. Through analyzing the problems existing in the cost control process, the comprehensive development of the project will not only improve but the pain points and difficulties in the project can also be timely and efficiently solved while effectively reducing the project cost to a certain extent in order to maximize the target profit. The earned value method does not only monitor the cost, but it also fully displays the direction of the cost use, and ultimately achieves the purpose of cost saving.

For the project, the ultimate goal is to ensure the quality of the project. If the cost value can be effectively reduced and at the same time, the quality level of the project can be ensured, a win-win situation of cost and benefit from the internal and external can be achieved along with the purpose of improving the advantages.

Cost control does not only ensure the steady progress of a project, but it also promotes the efficient use of resources. During a project, in addition to the control of time and space, the project can also take some control measures from the three-dimensional space. The strict supervision of a project requires the use of planned cost as the bottom-line benchmark as well as the effective and timely control of project progress. Cost control is conducive to promote enterprise engineering in order to achieve the purpose of profit. Obtaining economic benefits is the basic guarantee for the market to improve its competitiveness. Based on the development of the construction market, the operation and management ability of a construction 
enterprise lies in the sustainable development ability of the enterprise. Effective cost control is conducive to the considerable development of construction enterprises where it constantly improves their competitiveness and their cost control ability to a certain extent.

The disadvantages of earned value method include incomprehensiveness, contains only a few information, and it cannot be processed by a computer. In view of this, bar charts and tables can be used to supplement it. At the same time, the earned value method pays attention to the accuracy of data where it emphasizes the need for real-time monitoring and timely feedback information in a specific construction process.

\section{Application of earned value method in project cost management and schedule management}

The construction of a residential project, 2-2, started on April 15, 2019. The company took the work completion node on the keyline as the cost statistics as well as analysis point and calculated the earned value data once a month.

The actual cost and progress data of 2-2 building project in October 2019 has been collected and sorted out.

Actual cost: The actual cost in October 2019 (see Table 1 for the ACWP of the completed project in October 2019).

Progress data: In October 2019, the project progressed to the completion of the main body on the first and second floors of the main building, the main body on the first floor of the North podium, and the main body on the third floor of the South podium.

According to the actual cost in October, referring to the control target of project cost deviation and combining with the value of BCWS, the BCWP of the project is calculated, which is the earned value, EV (as shown in Table 1, Table 2, and Table 3).

According to the data and the theory of earned value method, the three basic indicators are calculated: project budget cost (or BCWS), actual cost of work (or ACWP), and budget cost of completion (or BCWP) (Table 1, Table 2, and Table 3).

Table 1. ACWP of the completed project of 2-2 building in October 2019

\begin{tabular}{ccc}
\hline Serial number & Unit project & Amount (yuan) \\
\hline 1 & Civil engineering & $1,152,425.37$ \\
2 & Decoration engineering & $60,143.52$ \\
3 & Water supply and drainage, heating engineering & $12,061.56$ \\
4 & Electrical engineering & $2,665.00$ \\
5 & Total & $1,227,295.45$ \\
\hline
\end{tabular}

Table 2. BCWS of 2-2 building in October 2019

\begin{tabular}{ccc}
\hline Serial number & Unit project & Amount (yuan) \\
\hline 1 & Civil engineering & $1,152,425.37$ \\
2 & Decoration engineering & $60,112.65$ \\
3 & Water supply and drainage, heating engineering & $12,167.76$ \\
4 & Electrical engineering & $2,600.00$ \\
5 & Total & $1,227,305.78$ \\
\hline
\end{tabular}


Table 3. BCWP of the completed project of 2-2 building in October 2019

\begin{tabular}{ccc}
\hline Serial number & Unit project & Amount (yuan) \\
\hline 1 & Civil engineering & $1,129,376.86$ \\
2 & Decoration engineering & $58,940.65$ \\
3 & Water supply and drainage, heating engineering & $12,302.79$ \\
4 & Electrical engineering & $2,691.65$ \\
5 & Total & $1,145,637.38$ \\
\hline
\end{tabular}

According to the values listed in the above table, the earned value method is used for calculation. According to the calculation, the cost variance in October 2019 is obtained as shown in the following table (Table 4).

Table 4. Project cost variance analysis in October 2019

\begin{tabular}{ccc}
\hline Serial number & Unit project & Amount (yuan) \\
\hline 1 & Civil engineering & $1,152,425.37$ \\
2 & Decoration engineering & $60,143.52$ \\
3 & Water supply and drainage, heating engineering & $12,061.56$ \\
4 & Electrical engineering & $2,665.00$ \\
5 & Total & $1,227,295.45$ \\
\hline
\end{tabular}

According to the cost data collected in October 2019, the cost variance (CV) and schedule variance (SV) are analyzed.

In the earned value method, the difference between the budget cost and the actual cost of the project is called cost variance in which the formula is cost variance $(\mathrm{CV})=$ earned value $(\mathrm{EV})$ - actual cost (ACWP). Based on the above analysis of CV value, the cost variance of the residential project in October 2019 is calculated:

$$
\mathrm{CV}=\mathrm{EV}-\mathrm{ACWP}=1,145,637.38-1,227,295.45=-81,658.07 \text { yuan }
$$

Schedule variance is the difference between the budget cost of the completed work and the budget cost of the planned work. It shows the result of the comparison between the current schedule or progress and the baseline schedule or progress (in time progress unit).

When SV is positive, it means that the current actual schedule or progress is ahead of the baseline schedule or progress, reflecting that the construction period performance is better, and the construction period is ahead of schedule.

When SV is negative, it means that the current work progress is behind the baseline schedule or progress, which reflects the poor performance of the construction period and the delay in the construction.

Therefore, combined with the actual data of the residential project in October 2019, the schedule variance of the residential project in October 2019 is calculated:

$$
\mathrm{SV}=\mathrm{EV}-\mathrm{BCWS}=1,145,637.38-1,227,305.78=-81,668.40 \text { yuan }
$$

Cost performance index (CPI) and schedule performance index (SPI). CPI measures the cost efficiency of ongoing projects; that is, in project management. 
The index used to measure performance is called cost performance index. The calculation formula of $\mathrm{CPI}$ is cost performance index $(\mathrm{CPI})=$ earned value (or BCWP) / actual cost of completed project (or ACWP)

When the CPI is less than 1 and gradually becomes smaller, the project should take specific measures. According to the actual data of the project in October 2019, the cost performance index of the residential project in October 2019 is calculated:

$$
\begin{gathered}
\mathrm{CPI}=\text { earned value } / \text { actual cost of completed project } \\
=\mathrm{BCWP} / \mathrm{ACWP}=1,145,637.38 / 1,227,295.45=0.93
\end{gathered}
$$

SPI, which is expressed as the ratio of earned value to planned value, is an indicator to measure progress performance. The schedule performance index can reflect the utilization of project time. Combined with the actual data of the residential project in October 2019, the schedule performance index of the residential project in October 2019 is calculated:

$$
\begin{aligned}
& \text { SPI }=\text { earned value } / \text { budget cost of the proposed project } \\
& =\mathrm{BCWP} / \mathrm{BCWS}=1,145,637.38 / 1,227,305.78=0.93
\end{aligned}
$$

\section{Conclusion}

Earned value management plays an indispensable role in project management. As a management tool with cost and construction period as the main control factors, its role is to control the whole project by cost control and shortening the construction period so as to ensure that the whole project is completed on schedule with certain benefits and effects along with a more integrated analysis of the project for the construction sector due to the relatively large number of personnel involved. However, the use of earned value method is relatively difficult and complex, in addition to its difficulty to achieve accurate budget results at times. Hence, there is a need to constantly sum up experiences and lessons to gradually promote and improve it in giving full play to the specific role of earned value management.

\section{Disclosure statement}

The author declares that there is no conflict of interest.

\section{Author contributions}

Wenjing $\mathrm{Xu}$ investigated the construction and management of rural highways and wrote the whole article.

\section{References}

[1] Du X, Xu Z, Sheng W, 2009, Improved Ammoniacal-Nitrogen Removal in Non-Planted Vertical FlowConstructed Wetland System by Natural Oxygen Transfer. Fresenius Environmental Bulletin, (10): 1846-50.

[2] Tubig SB, Abetti PA, 1990, Variables Influencing the Performance of Defense R\&D Contractors. IEEE Transactions on Engineering Management, (1): 22-30.

[3] Wang WC, Liu JJ, Chou SC, 2006, Simulation-Based Safety Evaluation Model Integrated with Network Schedule. Automation in Construction, (3): 341-54.

[4] Hao L, Bing D, Huang GQ, et al., 2013, Hybrid Flow Shop Scheduling Considering Machine 
Electricity Consumption Cost. International Journal of Production Economics, (2): 423-39.

[5] Kujawski E, Alvaro ML, Edwards WR, 2010, Incorporating Psychological Influences in Probabilistic Cost Analysis. Systems Engineering, (3): 195-216.

[6] Liang JS, 2010, An Approach for Generating a Tasks Schedule Model in Web-Based Virtual Manufacturing System of Screw Threads. International Journal of Advanced Manufacturing Technology, (5-8): 737-55.

[7] Lilly MT, Ihekwoaba SC, Ogaji S, et al., 2007, Prolonging the Lives of Buried Crude-Oil and NaturalGas Pipelines by Cathodic Protection. Applied Energy, (9): 958-70. 